\title{
The Urgency and Importance of Public Art Maintenance and Management Mechanism Establishing
}

\author{
Leyi Dong \\ Nanyang Institute of Technology, China
}

Keywords: Public art, Maintenance, Management, Mechanism

\begin{abstract}
Public art with unique artistic form in the public eye, made the various elements of city look downier, cultural history and city image closely linked together, it occupies the important status in the urban construction. Although China's urban public art has had the very big change, there have been some outstanding works, but the urban public art appeared in China's time is shorter, scientific maintenance and management of public art mechanism the urgency and importance of construction is especially unique.
\end{abstract}

\section{Introduction}

Einstein said: knowledge is limited, and art to develop people's imagination is unlimited. Public art in the aspect of talent cultivation with other disciplines irreplaceable role. It is an important part of the humanity quality education and the reform of college education important constituent. Including the purpose of public art education cultivate noble temperament and interest, cultivate aesthetic ability, to develop innovative thinking, rich emotional experience, improve the psychological quality, perfect personality development, etc [1]. Itis to improve people's sound personality psychological quality and personality of the needs of all-round development, is the need of improving people's ideological and moral quality, is the need of improving people's aesthetic ability, is to perfect knowledge structure, cultivate creative thinking of people's needs. But after study finds that the development of public art education has many problems, such as art education status is not high, the mechanism is not sound, system is not smooth, the lack of policy support and system guarantee, aesthetic education course lack of top-level design, etc.

Public art education belong to the category of aesthetic education, is the important way of beauty education. It is through art, music, dance, drama, etc. Of course or practice, it can help people set up the correct aesthetic culture, the development of public power to appreciate beauty and create beauty, edify people's sentiment, improve the citizens' mental state, in the whole education system plays an irreplaceable role, is an important part of quality education. Art education is a type of art education.

\section{Public art and its definition}

Public art in one form or another in the human history, from ancient Greek Public Square to 60 century environmental art in the United States, it is because of the historical and social functions are constantly changing, such as Fig.1. "This development process to achieve the three transformations, one is in the social function of art, has realized from the standpoint of the dominant ideology and national culture... the third is implemented on aesthetic form and connotation of art from artists express individual artistic experience and ideas, to a concern for the public aesthetic taste and aesthetic pursuit of life transformation." Today, because in different countries or areas, there is much difference between historical tradition and cultural background, the definition of public art views, but it has a consensus, "the public" is a public art as a form of modern art. Public art is in not to restrict the freedom of the public environment and get the public recognition, can coordinate the environment of the art of modeling, long-term or permanent [2]. 


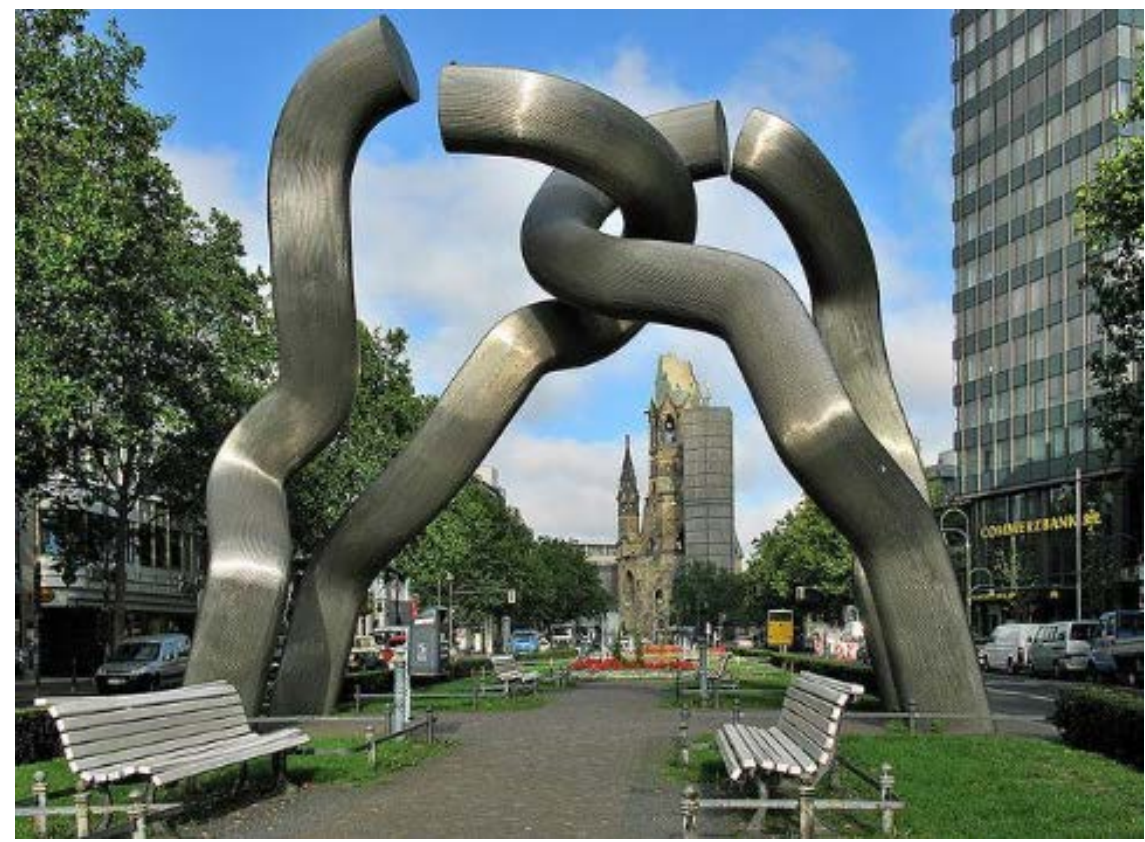

Fig.1 The form of public art

\section{The performance and characteristics of public art}

Public art as part of the People's Daily life, it brings in the form of various comprehensive artistic enjoyment of the broad masses of the people, and with the expansion of The Times change and the types of public art, it basically has the following features [2]:

Spatiality. The role of public art is very broad, but always cannot leave for construction of urban public service tenet. Public art play an irreplaceable role in urban construction, the combination of public art and landscape art, a unique feature of urban environmental art can also increase the public art to the height of environmental protection, so that people not only appreciate the art and environmental protection.

The public. Publicity is a necessary condition for the existence of public art, it gives the rights of the construction of the public to participate in public affairs. In the ancient system of feudal society, the royal garden sculpture how no matter how luxurious it has rich and fine, how beautiful garden. But that is the unique space of the royal family, is the representative of power, power replaced the publicity, publicity there no longer exists, so, the public is the product of social development, it is a democratic, open, also tightly linked together with the progress of mankind. The publicans of public art are the public to better participate in the construction of city and resource sharing.

Aesthetic. The existence of the public works of art as art has the certain aesthetic. "In this triangle kind of authors, works, and the public, the public is not a passive part, not only as a kind of reaction, on the contrary, his is a dynamic composition of history." Public art of the masses can the enjoyment on the vision, therefore public art should have aesthetic.

Leading. Perfect public art are general sense. Artists in the public works of art, he compared to ordinary citizens is relatively advanced way of thinking, the sculpture with its art gimmick interpretation of the subject will also because of people's artistic accomplishment and far.

\section{The urgency and importance of maintenance and management of public art}

As the national art education project meeting held successfully, and many of the programmatic document issued, visible state to the attention of the public art education. Public art is to cultivate high-quality talents and socialist modernization construction need to establish a more restrictive, in improving the aesthetic quality, cultivate the innovative spirit and practice ability, to shape healthy personality has an irreplaceable role. 
Urban public art category includes all of the landscapes in urban public space and related events, activities, big city sculptures, landmarks, monuments, buildings, large-scale cultural and artistic activities, etc.; Small, such as road signs, the putting, street lamps, telephone booth, trash can, fountain, public space of the trails, railing, chairs, public station, subway station, etc. The world famous art critic article south Shi Shang said: "no matter from architecture, urban planning, or the point of view of art, age is gradually turning its attention to the public art" [3]. At present, China in the aspect of city public art construction compared to domestic and foreign advanced cities and larger gap, obvious leakage and insufficient

The policy support is not enough, the system.For a long time, because different city public art construction implementation main body, the lack of a unified under centralized management department, the city planning department, municipal construction departments, the municipal party committee propaganda department, municipal culture bureau and other relevant units, and even the neighborhood offices in each city public art construction, not to the urban public art form effective supervision and management [3]. At the same time, the government in urban public art almost in a blank state laws, lack of punishment for illegal behavior of urban public art construction and constraints.

Public art construction capital channel. At present, the city public art construction the most prominent problem is mainly by government investment, lack of multi-channel investment policy, it is difficult to guarantee the sustainable development of public art construction. As the city haven't arrange the city public art construction fund. Some urban public art projects funded by developers or social capital, which creates a who investment, who's in charge, after the completion of urban public works of art are often not reached artistic effect [4]. At the same time, due to lack of urban public art construction funds into a big city with a modern appeal public works of art are rare in our city. The government to the urban public art construction funding uncertainties, is one of the factors which restrict the development of the city public art. At present, some cities as Beijing, Shanghai, nanchang, and even, started from urban construction funds arranged special funds for the including urban sculpture, urban public art construction. It is worthy of reference for our city.

The lack of system planning urban public art. Now often attributable to urban construction projects, urban public art construction is commonly said project project, the lack of a system planning. Layout in the city often cause public art subject matter a single repetition, homogeneity phenomenon serious, and because of the different implementation main body, easy to cause the city public art artistic quality good and bad are intermingled [4]. Even some architecture and sculpture to feng shui, exorcism, such as superstition purposes, not only caused atrophy and degeneration of the imagination, and became the public visual pollution.

\section{Public art mechanism of maintenance and management advice}

Set up the system of "city city public art percentage".Percentage of the so-called "public art", that is, the government in the form of legislation, draw a certain proportion from the engineering construction investment funds, used for creation and construction of urban public works of art. In 1956, the Philadelphia became the world's first implementation of the "percentage of public art policy" of the city [5]. After half a century of practice, "percentage of public art policy" as some developed countries and promoting universal city urban cultural taste, mature experience to improve urban residential environment.

To build a "city of city public art construction committee of experts".Learn from excellent city set up the practice of urban planning expert committee, suggested on the basis of city planning, urban construction, organize relevant experts, scholars, professionals and citizens on behalf of the city, urban public art construction experts committee, as the city public art construction management organization, construction of the city public art practice guidance and to manage. Main responsibilities include: the use of urban public art fund supervision, for large public art creation and review was laid, to guide a citywide public art activities, to assess public art special award, etc., ensure the orderly and healthy urban public art construction, urban public art construction to avoid blind and disorder [6]. Now, after the public art fund can be used to improve the public art and design, 
we can design the more beautiful a telephone booth, bus station, public sculpture, can also be used for the improvement of the park, art galleries and other public facilities.

Reserve "build" city public art project.Take government development, collect, individuals, society paid design such as a variety of channels, in particular, make full use of expert resources platform, make public art projects planning and reserves, to establish "urban city public art project reserve". By regularly for the project, in a timely manner will be able to reflect the urban geographical features, history and culture, or the modern public art reserve project to the market, the construction of a batch of public art projects in a big way [5]. At present, special attention should be paid to the city public art construction and the city "four development priority zones" important urban construction projects, such as "the round-the-city water", completes the relevant planning, appropriate node arrangement of urban public art landscape in the city, to build the international first-class standard of modern livable beautiful city art atmosphere.

To establish "long-term mechanism of urban public art". Will be held at regular "PingJu art festival", "ceramic fair", on the basis of hold more various forms, rich contents of city public art festival or regularly host city public art BBS, invites well-known artists at home and abroad to participate in activities, collect good art and art planning case, so as to raise public awareness of the city, city image and city competitiveness [7]. At the same time, accelerate the city grand theater, the city museum city landmarks such as construction, building performance, ornamental, memorial, which integrates multi-functional theater, to meet the domestic first-class and world-class performance art groups, concerts and other kinds of the needs of the program. Strengthen the city square, city sculpture, street parks, bus stations, the construction of urban public space, urban construction and cultural elements combine effectively, increase the cultural function of public places, as far as possible reflect culture, for the masses to provide a higher level of public space.

\section{Conclusion}

Chinese urban public art development, achieved fruitful results, have sprung up in the city of a batch of a batch of excellent city sculptures. They improve our level of artistic accomplishment, and culture, but the ascending that how also can't keep up with the artist's artistic accomplishment lead art consciousness, the artist's prospective in today's society are not completely of public recognition, so the maintenance and management mechanism of public art have the urgency and the importance of time.

\section{Acknowledgement}

2017 annual project topic of Henan province philosophy social sciences planning office, Project name: "The urgency and importance of public art maintenance and management mechanism establishing”.

\section{References}

[1] H.S. Zheng, Public art in China, Shenzhen, Hong Kong cardiac fine arts publishing house, 2004.vol.2, pp.26-30.

[2] X.Y. Zhang, Implementation Percentage of public art policy in Chinese cities, The Chinese building, 2010, vol.8, pp.48-51.

[3] H.T. Wang, Aesthetic quality of art education, Changsha: Hunan normal university press, 2005, vol.2, 23-27.

[4] L.Q.Li, Education interviews, Beijing: people's education press, 2014, vol.4, 14-17.

[5] Q.Z. Ma. The basic theory of public art, Tianjin: Tianjin university press, 2008.vol.2, pp.18-21.

[6] Y.F. Feng. City sculptures, you don't betray "public", The Chinese culture, 2006, vol.5, pp.32-35. 
[7] L.L. Ran. New form of preliminary study on urban public art, Beauty and age, 2012 vol.1, pp.12-15. 